Article

\title{
The Spatial Factors of Cultural Identity: A Case Study of the Courtyards in a Historical Residential Area in Beijing
}

\author{
Zhifen Cheng ${ }^{1}$, Shangyi Zhou ${ }^{2, *}$ and Baoxiu Zhang ${ }^{1, *}$ \\ 1 Institute of Beijing Studies, Beijing Union University, Beijing 100101, China; zhifencheng2004@163.com \\ 2 Faculty of Geographical Science, Beijing Normal University, Beijing 100875, China \\ * Correspondence: shangyizhou@bnu.edu.cn (S.Z.); baoxiu@buu.edu.cn (B.Z.)
}

Received: 31 May 2018; Accepted: 18 July 2018; Published: 24 July 2018

check for updates

\begin{abstract}
The issue of identity is very complex and determining the factors influencing cultural identity is a key issue. Several scholars have studied the factors influencing cultural identity. However, relatively little attention has been paid to how spatial factors influence cultural identity. This paper takes a historical and cultural conservation block in Beijing, China, as the research area. This area includes eight lanes and is called Eight Lanes in North Xisi. The purpose of this paper is to demonstrate that spatial changes in living conditions, layout, size, architectural form, and decoration, etc. in the courtyards led to changes in the traditional culture of the courtyards, which ceased to reflect the original residential culture, which led to a decline in cultural identity. Spatial factors directly affected the residents' cultural identification with harmonious courtyard culture. This view adds nuance to debates about cultural identity and the factors that influence it. From the perspective of cultural geography and by using structural equation modelling, we draw two main conclusions. First, the smaller proportion of public space (The term "space" as it is used in this paper is based on the understanding of humanistic geographers and refers to physical space; it does not acquire meaning and cultures.) is one main factor affecting residents' identification with the harmonious residential culture of the case area. Second, the greater population density of the courtyards is another main factor affecting residents' identification with the area's harmonious residential culture.
\end{abstract}

Keywords: residential culture; cultural identity; influencing factors; structural equation model

\section{Introduction}

The word "identity" comes from the Latin word "idem", meaning "sameness". Identity can be understood as acknowledging and agreeing with which one identifies. The issue of identity came to the fore during the regionalization process of the 1980s [1]. It is considered necessary to distinguish between "I" and "the other" to produce common action [2]. Identity can create social and cultural cohesion [3]. Cultural identity is a description of self-characteristics [4]. It involves citizenship and a sense of belonging [5] and is the basis for the formation of other types of identity. Indeed, some scholars believe that cultural identity is the basis for the formation of national identity, ethnic identity, local identity, and political identity [6].

The issue of identity is very complex and has been the subject of in-depth studies in the fields of semiology, sociology, environmental psychology, and architectural criticism, etc. One of the key questions of such studies is, "What are the factors influencing cultural identity?" Several scholars have studied these influencing factors, including individual attributes, the external environment, and the combined effects of these factors.

First, with respect to individual attributes, sociologist Bernard Lazerwitz from Indiana University proposed that, in addition to conventional factors such as education, religion, and friendship, the factors 
influencing Jewish cultural identity include unique aspects of Jewish culture, such as Zionism [7]. Sociologist Ralph Segalman from Indiana University suggested that the Jewish lifestyle is also a factor influencing Jewish cultural identity [8]. Scholar Leo Driedger of the University of Manitoba studied the factors influencing cultural identity in students of different ethnicities at the University of Manitoba. He found six factors influencing cultural identity, which, in order of decreasing importance are religion, endogamous marriage, language use, ethnic groups, education, and friendship. Second, the factors influencing cultural identity differ across ethnic groups. For example, the factors influencing Jewish identity are mainly kin marriage, friendship, and education, but the factors influencing French identity are language and religion, etc. [9]. Scholars Susham Gupta and Dinesh Bhugra of the Central and North West London NHS Foundation Trust hold that the factors influencing cultural identity include attitude, religion, and religious rituals, eating habits, and clothing [10].

Second, with respect to external environment factors, geographer Peter Gold of the University of the West of England stated that the factors influencing cultural identity are historical, political, and cultural. He studied the factors influencing residents' cultural identity in Gibraltar. Eighty percent of residents had been born in Gibraltar, and their families had lived there for several generations. The study found that residents in Gibraltar were more willing to identify themselves as British Gibraltarian or English than as Spanish. The factors influencing residents' cultural identity in Gibraltar were mainly historical, political, and cultural. First, the historical factors include the fact that Spain implemented a 16-year blockade and quarantine of Gibraltar beginning in 1969. Because Gibraltar relied heavily on Spain for daily supplies, transportation, traffic, and communication, etc., this isolation made daily life difficult for residents of Gibraltar. Second, regarding the political factors, residents of Gibraltar believe that the Spanish government continues the despotism of the Franco era and its claim to ownership of the territory. Moreover, most government officials in Gibraltar are English. Third, with respect to cultural factors, Gibraltarians have lived in Gibraltar under British culture for an average of six generations [11]. Hosna Shewly, a geographer at Durham University, agreed with Gold's assessment, indicating that, at present, the residents of Gibraltar do not identify with the Spanish culture at their border because Britain and Spain have a history of conflict over Gibraltar's sovereignty, and the residents in Gibraltar have accepted British culture out of habit [12]. Katarina Szulenyiova, a geographer at the University of Cambridge, also agreed with Gold's perspective and asserted that the most important factors influencing the residents' cultural identity were political [13]. Lahoud A.L. from Lebanese American University argued that the unique architecture of Lebanese dwellings and their history play important roles in the identity of the Lebanese community and nation [14]. Lucia Martinez-Quintana and Eduardo Caceres-Morales of the University of Las Palmas, Spain, performed a case study of cultural identity on the Island of Saint-Louis, Senegal, and reported that the factors influencing cultural identity are political, social, and economic factors related to functional transformation [15].

Third, with respect to comprehensive factors, Nechitaylo Vladimir of the National Academy of Managerial Staff of Culture and Arts Herald in Ukraine has noted that culture and art, including customs, cultural traditions, language, and religion, are the key factors of national cultural identity. Folk choreography is also an important factor in the formation of individual and collective national and cultural identity [16]. Schwartz, S.J. and Zamboanga, B.L. et al. of the University of Miami and Swarthmore College investigated 349 emerging-adult students in the USA with different heritage-culture identities in order to examine the structure of cultural identity. They considered three variables in the study: familial ethnic socialization, perceptions of discrimination, and acculturative stress. The results showed that these variables interacted to influence cultural identity [17].

In addition to these factors, cultural identity is also related to spatial factors. This paper adds nuance to debates over the factors shaping identity and demonstrates the influence of spatial factors from the perspective of cultural geography. This paper takes Eight Lanes in North Xisi, a historic preservation area in central Beijing, as the research area and uses structural equation modelling (SEM) to study residents' cultural identification with the area's harmonious residential culture. 


\section{Research Area's Residential Culture}

\subsection{Eight Lanes in North Xisi}

The Eight Lanes in North Xisi were constructed in the Yuan Dynasty (1276-1285). The zone was one of "Beijing's first batch of historical and cultural protection zones" established in 1990, and it is one of the most representative residential areas formed by lanes among the 25 historical and cultural districts in the old city of Beijing.

During the Yuan dynasty, the Eight Lanes in North Xisi were located in the southwest part of the city. Influenced by the urban road pattern, the area comprised eight parallel lanes. In the first half of the Ming Dynasty, the north wall and the south wall of Beijing City moved to the south, and the zone was located in the northwest part of the city. After the second half of the Ming Dynasty, a new outer city was built in Beijing that was based on the inner city, and the Eight Lanes in North Xisi were located in the north part of the city. At present, the protected area is located in northwest Beijing in the Xicheng District and is under the jurisdiction of the Xinjiekou Subdistrict Office. The relative location of the Eight Lanes in North Xisi in the old city of Beijing is shown in Figure 1.

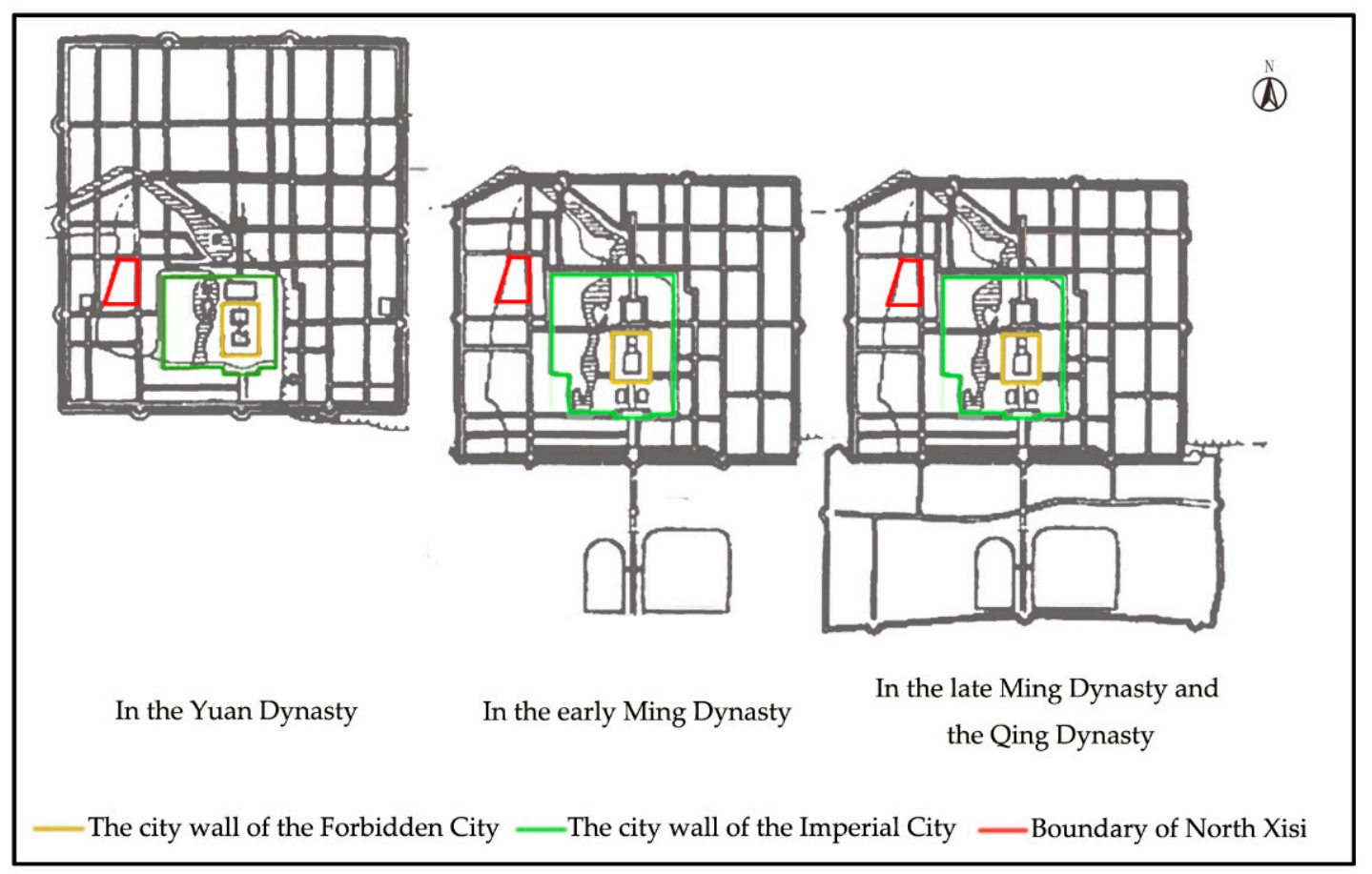

Figure 1. The relative location of the Eight Lanes in North Xisi in the old city of Beijing.

At present, there are 576 door numbers in the area, including a total of 3870 registered households and more than 1000 registered floating population households, with 9942 permanent residents [18]. Its northern boundary is along E. Pinganli Street, the southern boundary is N. Xisi 1st Lane, the western boundary is Zhao Dengyu Road, and the eastern boundary is N. Xisi Street. From south to north, these lanes are respectively N. Xisi 1st Lane, N. Xisi 2nd Lane, N. Xisi 3rd Lane, and so on to N. Xisi 8th lane (Figure 2). 


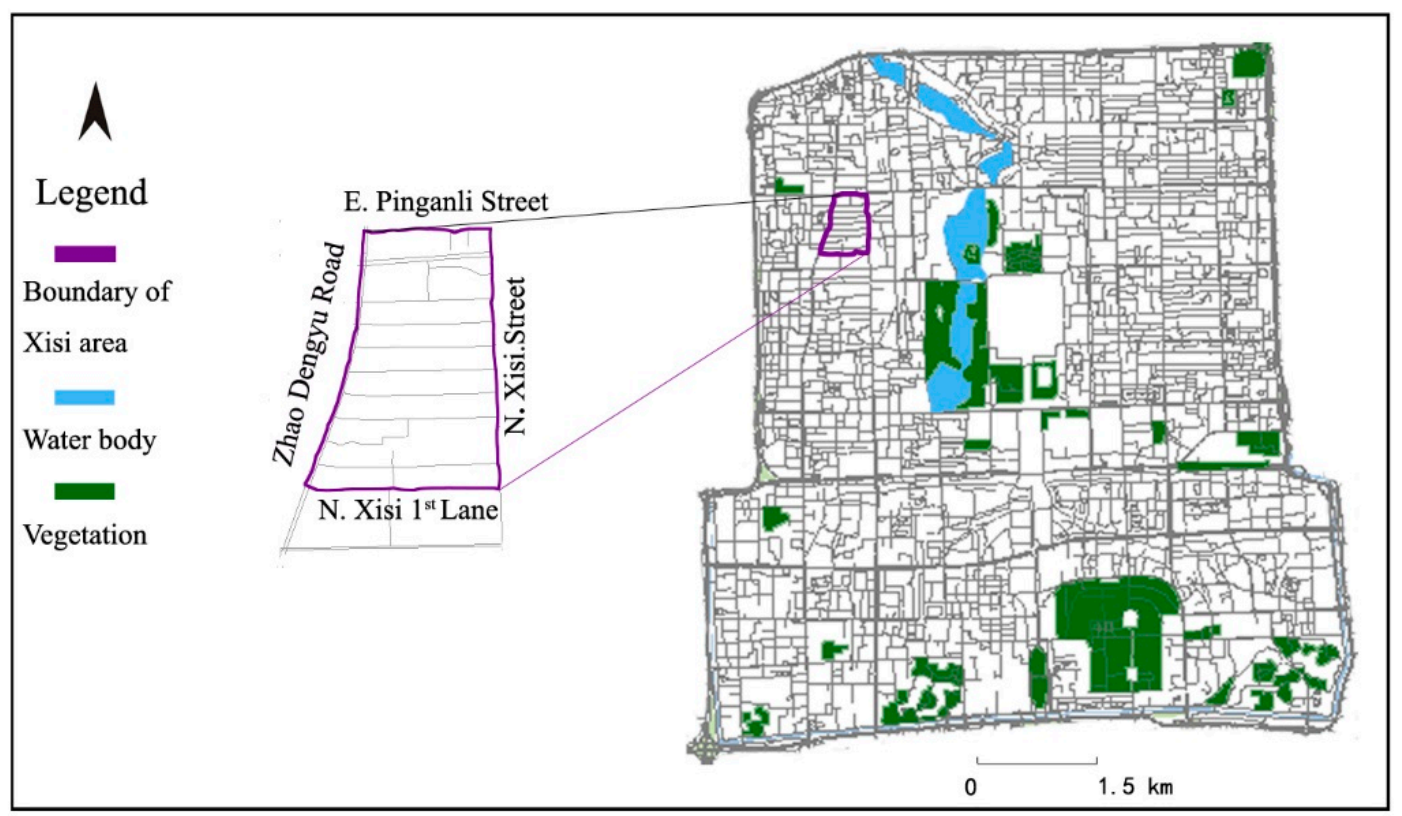

Figure 2. The range and location of The Eight Lanes in North Xisi in the old city of Beijing.

\subsection{Residential Culture in the Study Area}

As a traditional residential area with more than 700 years of history, the Eight Lanes in North Xisi area has a rich traditional culture. This traditional culture is represented in three spatial details: the layout and size, the architectural form, and the decoration of the courtyards. First, the courtyards in the area have different layouts and sizes corresponding to the different ranks of officials in the Ming and Qing dynasties. For example, in the 26th year of Hongwu (1393), officials of the first and second ranks had a five-room, nine-frame hall; officials of the third, fourth, and fifth ranks had a five-room, seven-frame hall. Commoners' dwellings could not exceed a three-room, five-frame hall [19]. Second, there are structures in different locations and with different forms in a single courtyard, including the principal rooms, wing rooms, side rooms, and reverse-facing rooms, and the statuses of those who lived in these structures were different: elders usually lived in the principal room, and the servants usually lived in the reverse-facing rooms. This distinction reflects traditional Chinese culture in its emphasis on priority by rank and respect for seniority $[20,21]$. Third, in the Ming and Qing dynasties, the decorations and locations of the houses differed according to the hierarchical status of the residents. For example, in the Guangxu period (1871-1908), for officials above the second rank, Watch Animals could be placed on the ridges of the roof. For officials of the third rank, the doorposts were decorated with black chalk. For officials below the fourth rank, the doorposts were painted with flowers [22]. The form of the gate and style of the quadrangle courtyards also reflected the status of the residents. For example, in the 8th year of the reign of Emperor Shunzhi (1651), the door steps were two chi high ("chi" is an ancient unit of measure in China; one chi is approximately 31 centimeters) for officials of the first through third ranks and one chi high for officials below the fourth rank and commoners, and the door was decorated with black [22]. In addition, the building decoration in the courtyards primarily depicts plants, animals, ancient artefacts, and combinations of patterns; the representational culture is depicted using traditional symbols of good fortune, with the inspirational culture and ethical culture expressed through homophonic, consonant, and hieroglyphic methods (Figure 3) [19,23].

The layout and size, architectural form, and decoration in the courtyards express traditional Chinese culture by adherence to the principles of priority by rank and respect for seniority and in the use of traditional symbols of good fortune and of inspirational culture and ethical culture. Indirectly, these spatial details also express a harmonious neighborhood relationship. Therefore, the core culture represented by these three spatial aspects is "harmonious culture". Historically, the Chinese gradually accepted 
and identified with this living pattern and traditional culture [24]. The origin of this identity is traditional Chinese philosophy $[25,26]$. Although the philosophy of harmoniousness had historical limitations in Chinese feudal society and was embodied in a certain class structure, its pursuit of humility, respect and other excellent moral qualities; its focus on pursuing social stability with people living in peace and contentment; the patriotic national spirit; and the innovative spirit of the times were all consistent with today's idea of "harmony" [27]. The rites and ethics of the culture of representation embody harmony between people, and the optimism and inspirational culture embody that between man and nature [28].

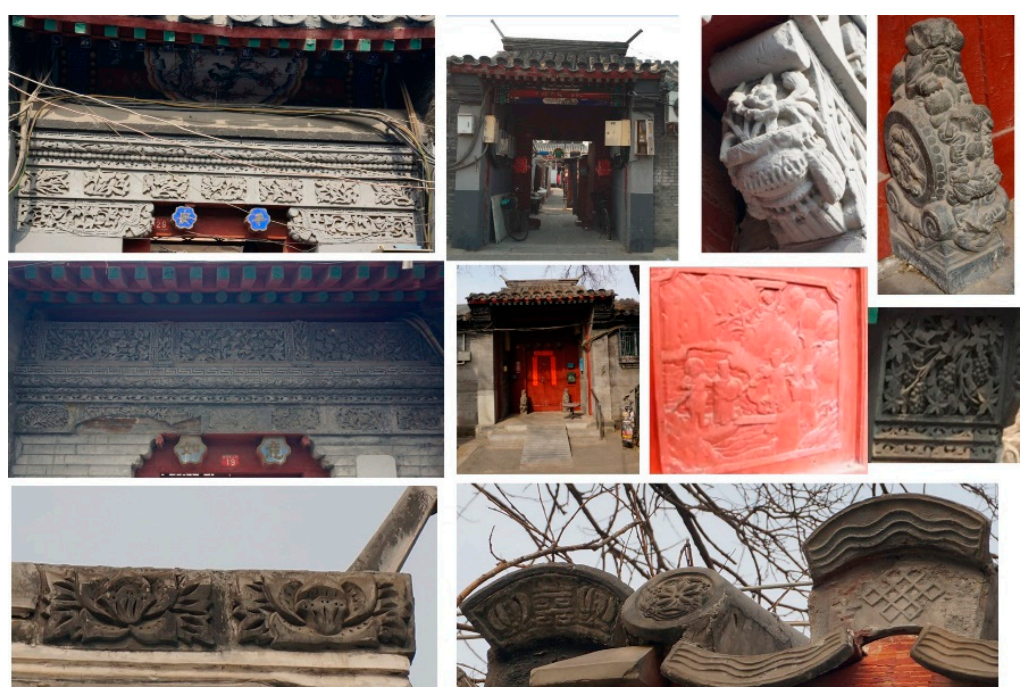

Figure 3. Representational forms in courtyards in the Xisi area.

However, two points deserve further discussion. First, the courtyards' size, location, decoration, and other characteristics have changed, and they are not the same as in the past due to changes in the living conditions in these courtyards and due to Chinese architecture's civil structure (Figures 4 and 5). Second, these characteristics are almost entirely uniform in the courtyards in North Xisi. Therefore, the changes in the courtyards and architecture have made depleted them of architectural meaning and made them unrecognizable.

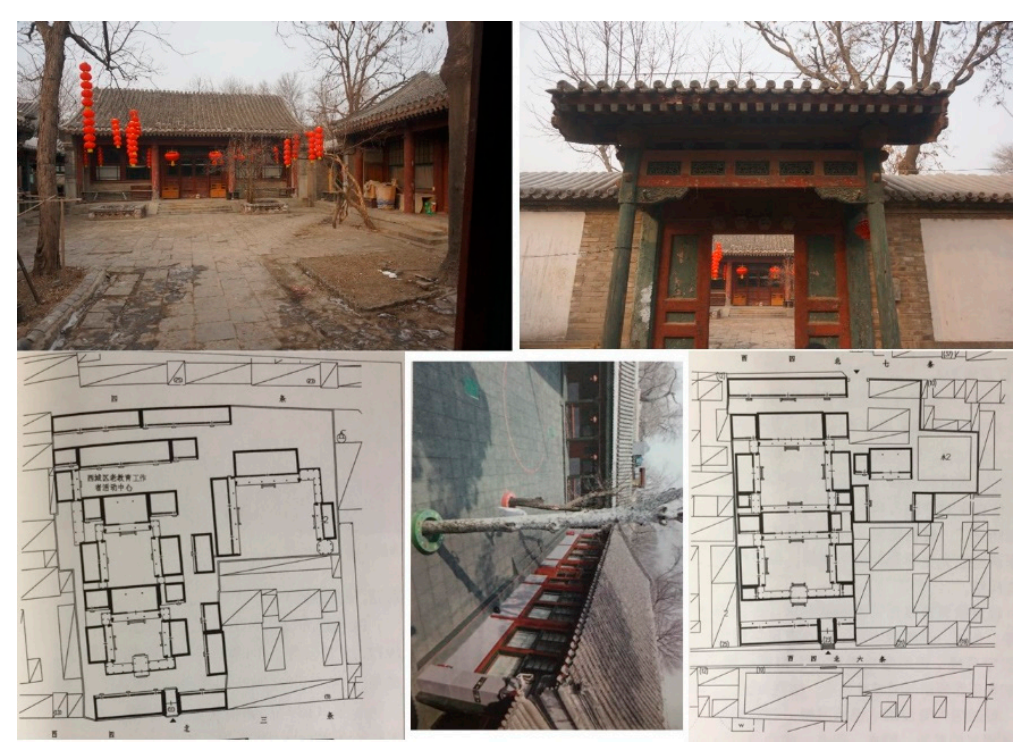

Figure 4. Courtyards in the Xisi area as they appeared in the past [19]. 

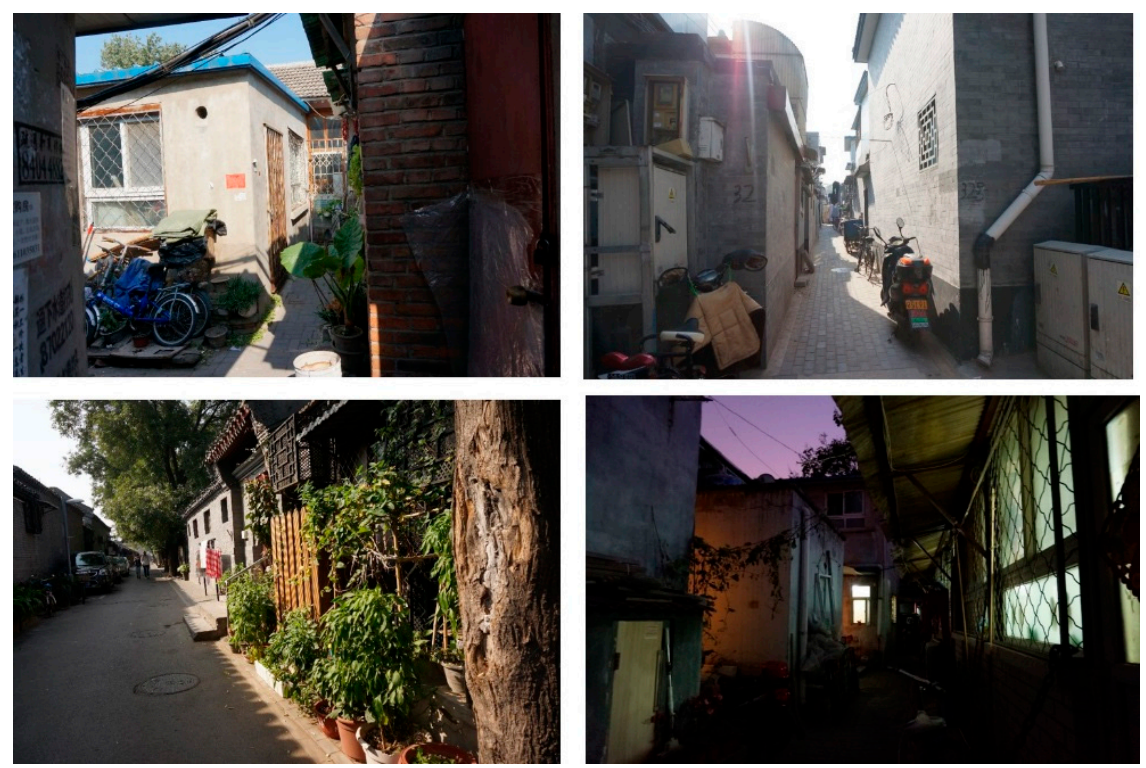

Figure 5. Courtyards in the Xisi area as they appear today.

\section{Research Methods and Data Sources}

\subsection{Research Methods}

According to Ellis, Barry and Robinson, who are scholars in the architecture school at Queen's University in Belfast, UK, quantitative methods are usually adopted to study changes in people's feelings and attitudes toward a place to understand their cultural identity [29]. Stedman, from Pennsylvania State University in the United States, also notes that cultural identity is usually measured quantitatively [30].

In our paper, SEM is used for the following reasons: first, SEM overcomes the shortcomings of traditional methods of cultural identity research, which are typically based on the simple probability statistics of the interview content or a simple questionnaire. Furthermore, SEM can be used to analyze the relations among the factors and influential elements of cultural identity, making it more scientific, comprehensive, and objective. Second, SEM is a multivariate analysis framework that integrates path, factor, and regression analyses and can use measurable observable variables to analyze the non-measurable latent variables of "harmonious culture" [31]. Third, SEM overcomes the shortcomings of traditional analytical methods (e.g., multiple regression and path analysis) caused by measurement errors with observable variables. SEM also offers the advantages of modelling multiple variables and the ability to examine the overall fit of the model. However, one of the features of SEM is that the initial model settings usually do not fit the data well, and the model needs to be modified and verified with the same data [32]. Our purpose is to analyze the theoretical assumptions of this paper and improve the adaptability of and simplify the model.

\subsection{Model Building}

Based on the existing research results and combined with the actual situation in this case, SEM is performed in this paper with four latent variables: living conditions of the courtyard, living conditions of one's own house, organization in the courtyard, and identification with a harmonious culture. The latent variables and observable variables of this model are shown in Figure 6 and Table 1. The variables and paths are designed based on the following: (1) According to Pettigrew, the nature and size of neighborhoods influence the link and contact between them, which in turn influence cultural identity [33]. Allport noted that neighborhoods are an important venue for intergroup contact [34]. Zhou Shangyi found that the proportion of out-of-towners living in a courtyard influenced residents' 
identification with the residential culture [24]. Xue Rui observed that the residential conditions of courtyards in the Xisi district were closely related to the number of households, the number of people, and the per capita area [35]. Michelson found that an excellent physical environment was more conducive to promoting neighbors' culturally required behavior [36]. Based on these findings, the four observable variables labelled $\mathrm{C} 1-\mathrm{C} 4$ were used in this paper to evaluate the latent variable of "living conditions of the courtyard", and a path of positive influence (H3) from "living conditions of the courtyard" to "identification with a harmonious culture" was assumed. (2) According to research by Hanif, Hashemnejad, and Ghafourian, physical comfort depends on proper living conditions, and physical discomfort can lead to psychological discomposure [37]. Muller proposed that some behavioral norms are the result of cultural traditions and clearly have spatial implications. Thus, limitations to space should be adjusted by, for example, manipulating perceived distance [38]. Through investigation of the courtyards in the Xisi district, Li Yingbo et al. found that most residents believed it was necessary to increase the size and number of houses, as their living conditions limited their identification with courtyard culture and residents would be more harmonious if their living conditions improved [39]. According to these findings, the latent variable of "living conditions of one's own house" was determined in this paper by four observation variables labelled S1-S4, and a path of positive influence $(\mathrm{H} 2)$ from "living conditions of one's own house" to "identification with a harmonious culture" was assumed. (3) Plummer argued that non-governmental civil society could play a positive role in mediating conflicts and resolving disputes and could strengthen the cultural identity of residents [40]. Zhou Shangyi and others have found that residents of courtyards in the Xisi area that have authority figures are more harmonious [24]. According to Carmona, De Magalhaes and Hammond, space organizers set rules, maintain facilities, and clean up garbage for all space users [41]. Jiao Yixue also asserted that when the central figure of the courtyard participates and acts as a moderator in the courts, the needs and desires of the residents are valued and respected, and the residents' identification with a harmonious culture can be strengthened [42]. Wang Liang suggested that residents can strengthen their sense of belonging and identity if they are organized to cope with unexpected events [43]. Based on these studies, "organization in the courtyard" is assigned three observable variables, $\mathrm{O} 1-\mathrm{O} 3$, and a path of positive influence (H5) from "organization in the courtyard" to "identification with a harmonious culture" was hypothesized. (4) According to Hanif, Hashemnejad, and Ghafourian, spatial organization can be studied as a method of expressing certain sets of cultural norms [37]. This paper thus assumes a path of positive impact (H4) from "living conditions of the courtyard" to "organization in the courtyard". (5) Smith asserted that houses that fail to take adequate account of the structure and needs of residents do not consider the unique identity of local cultural tradition [44]. Cui Hui and others noted that historically, the public space of quadrangle courtyards was a place for residents to communicate with each other, and residents formed harmonious neighborhood feelings in such spaces [45]. Some scholars have suggested that sustainable dwellings require large open spaces [37]. Moreover, according to Wang Zhenzhen, the traditional public space of the historical district contributed to a harmonious neighborhood life [46]. Upon investigation, Liu Yuanxin found that in Beijing quadrangle courtyards, many households currently forcibly occupy the public space (by building additions to houses, storing clutter, etc.), and it is not uncommon for residents to expect each other to mind their own business, which results in poor public health conditions and frequent conflicts among residents [47]. Zhou Kejing and others argued that the small, crowded public space of Beijing quadrangle courtyards has negative effects on residents, severely affecting their mood and identification with the residential culture [48]. Accordingly, four observable variables, M1-M4, are assigned to the latent variable "identification with a harmonious culture". (6) Yuan Xi found that in modern quadrangle courtyards, the size and number of rooms in a house are directly proportional to the income of the family, which is also directly proportional to the number of households and the number of residents in the courtyard [49]. Thus, this paper assumes a path of positive impact (H1) from "living conditions of the courtyard" to "living conditions of one's own house". (7) Zhou Shangyi reported that in many of the courtyards in the Xisi district, there are 
key individuals in the courtyard who have more control over the spatial discourse and more resources and shoulder more responsibilities, such as cleaning the courtyard, collecting public electricity fees, dredging the toilets, and resolving neighborhood conflicts [24]. Accordingly, this paper assumes a path of positive influence (H6) from "living conditions of one's own house" to "organization in the courtyard".

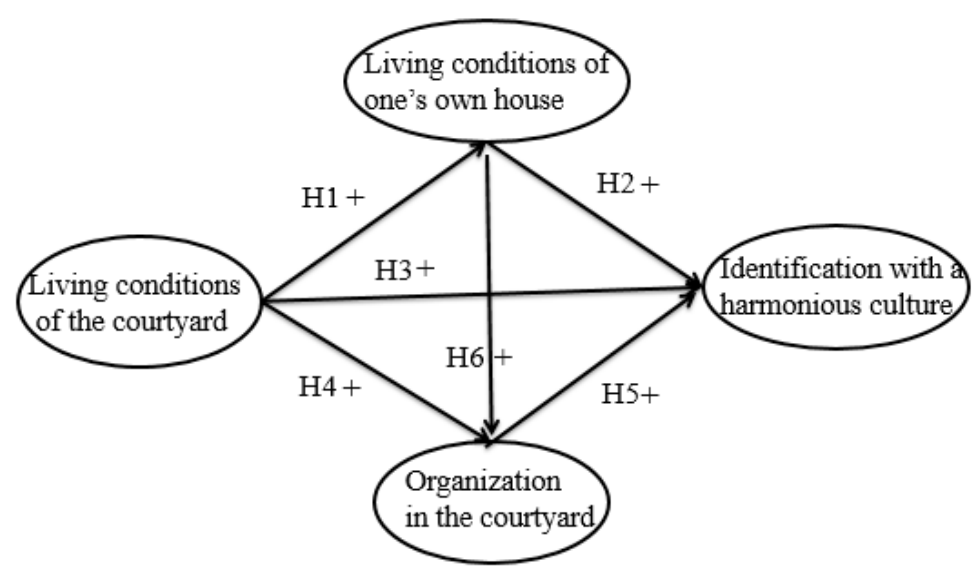

Figure 6. Path model of the latent variables.

Table 1. Latent and observable variables.

\begin{tabular}{cl}
\hline \multicolumn{1}{c}{ Latent Variables } & \multicolumn{1}{c}{ Observable Variables } \\
\hline \multirow{3}{*}{ Living conditions of the courtyard } & C1 Number of households \\
& C2 Number of people \\
& C3 Number of strangers \\
& C4 Per capita area \\
\hline \multirow{2}{*}{ Living conditions of one's own house } & S1 Area of one's own house \\
& S2 Number of rooms \\
& S3 Property rights \\
& S4 Length of residence \\
\hline \multirow{3}{*}{ Organization in the courtyard } & O1 Support for conflict resolution \\
& O2 Ability to cope with unanticipated problems \\
& O3 Approach to conflict resolution \\
\hline \multirow{2}{*}{ Identification with a harmonious culture } & M1 Use pattern of public spaces \\
& M2 Forms of mutual assistance \\
& M4 Use of public spaces \\
\hline
\end{tabular}

\subsection{Questionnaire Design and Investigation}

The questionnaire designed for this paper has three parts. The first part collects information on the basic attributes of the residents, including the address of residence, age, sex, occupation, and monthly income. The second part surveys residents' understanding of and identification with the area's harmonious culture. The third part is a survey of the observable variables. Residents responded to most of the items using a 5-point Likert scale ranging from 1 to 5, which indicate more or less favorability, respectively. In this study, a higher score indicated greater perceived harmoniousness of the culture. The characteristics of the survey conducted in the Eight Lanes in North Xisi are shown in Table 2. 
Table 2. Characteristics of the survey conducted in the Eight Lanes in North Xisi.

\begin{tabular}{|c|c|c|c|c|}
\hline Method & & Steps & $\begin{array}{l}\text { Effective/Total Respondents, } \\
\text { Effective Response Rate }\end{array}$ & Time of Investigation \\
\hline $\begin{array}{l}\text { Stratified quota random } \\
\text { sampling (This method saves } \\
\text { time, manpower, and material } \\
\text { resources; can be used to } \\
\text { calculate the overall index value } \\
\text { using the survey values of a few } \\
\text { individuals, and can ensure the } \\
\text { representativeness of the } \\
\text { sample [50].) }\end{array}$ & (1) & $\begin{array}{l}\text { According to the number of } \\
\text { courtyards in each lane and the } \\
576 \text { total courtyards in the area, } \\
115 \text { samples are divided into } \\
\text { eight lanes in this area. } \\
\text { In each lane, the quota of men } \\
\text { and women is the same, as is the } \\
\text { ratio of locals to out-of-towners. } \\
\text { Under these conditions, random } \\
\text { sampling is performed. Each } \\
\text { courtyard receives } \\
\text { one questionnaire. }\end{array}$ & $\begin{array}{l}104 / 115,90.43 \% \\
\text { (The sample size conforms to the } \\
\text { requirement for SEM, as some } \\
\text { scholars believe that calculations } \\
\text { can be performed as long as the } \\
\text { sample size is greater than } 65 \text {, } \\
\text { and some believe that the sample } \\
\text { size should exceed } 100 \text { [51].) }\end{array}$ & From May to June 2015 \\
\hline
\end{tabular}

\section{Data Processing and Model Checking}

In this paper, means were used in cases of missing data, and the abnormal data were checked, corrected, or eliminated. Some items take the form of ratio variables (such as per capita area), and scale conversion is thus performed to convert ratio variables into nominal level variables, divided into five levels. The missing value for the ratio variables was substituted with the "sequence mean" in SPSS before conversion into a nominal level variable. AMOS17.0 software was used for analysis.

\subsection{Analysis of the Demographic Characteristics of the Respondents}

The demographic characteristics of the respondents are shown in Table 3. The survey respondents were evenly distributed across the professions and stably employed. They represent the backbone of society and range in age from 26 to 74 . The questionnaire adequately reflects the demographics of residents in the region.

Table 3. The respondents' demographic characteristics.

\begin{tabular}{|c|c|c|c|c|c|c|c|c|}
\hline $\begin{array}{c}\text { Place of } \\
\text { Residence }\end{array}$ & $\begin{array}{c}\text { 1st } \\
\text { Lane }\end{array}$ & 2nd Lane & 3rd Lane & 4th Lane & 5th Lane & 6th Lane & 7th Lane & 8th Lane \\
\hline Number & 15 & 14 & 15 & 20 & 12 & 11 & 9 & 8 \\
\hline Proportion (\%) & 14.4 & 13.5 & 14.4 & 19.2 & 11.5 & 10.6 & 8.7 & 7.7 \\
\hline Profession & $\begin{array}{r}\mathrm{Te} \\
\text { worke } \\
\text { une }\end{array}$ & $\begin{array}{l}\text { nporary } \\
\text {, laid-off or } \\
\text { mployed }\end{array}$ & $\begin{array}{r}\text { Indi } \\
\text { busin }\end{array}$ & $\begin{array}{l}\text { idual } \\
\text { ssman }\end{array}$ & $\begin{array}{l}\text { Contract } \\
\text { worker }\end{array}$ & $\begin{array}{l}\text { Full time } \\
\text { worker }\end{array}$ & \multicolumn{2}{|c|}{$\begin{array}{l}\text { Public office } \\
\text { position }\end{array}$} \\
\hline Number & & 10 & & & 17 & 34 & \multicolumn{2}{|c|}{23} \\
\hline Proportion (\%) & & 9.6 & & & 16.4 & 32.7 & \multicolumn{2}{|c|}{22.1} \\
\hline Age (years) & & $\leq 25$ & & & $40-59$ & $60-74$ & \multicolumn{2}{|c|}{$\geq 75$} \\
\hline Number & & 2 & & & 31 & 23 & \multicolumn{2}{|c|}{13} \\
\hline Proportion (\%) & & 1.9 & & & 29.8 & 22.1 & \multicolumn{2}{|c|}{12.5} \\
\hline $\begin{array}{l}\text { Monthly income } \\
\text { (RMB) }\end{array}$ & & 2000 & 2000 & 5000 & $5000-7000$ & $7000-10,000$ & \multicolumn{2}{|c|}{$>10,000$} \\
\hline Number & & 19 & & & 11 & 4 & \multicolumn{2}{|c|}{9} \\
\hline Proportion (\%) & & 18.3 & & & 10.6 & 3.8 & \multicolumn{2}{|c|}{8.7} \\
\hline
\end{tabular}

\subsection{Model Reliability and Validity Test}

First, confirmatory factor analysis was performed on the variables of the harmonious cultural identity survey. The results showed that the Kaiser-Meyer-Olkin (KMO) value of the factor analysis quality test was 0.600 , greater than 0.5 , indicating that factor analysis could be performed [52]. The significance (Sig.) of the data was 0.000, which was less than 0.001 and passed Bartlett's test, indicating that the survey variables of the questionnaire were suitable for factor analysis (Table 4). 
Table 4. KMO and Bartlett's Test ${ }^{\mathrm{a}}$.

\begin{tabular}{ccc}
\hline Kaiser-Meyer-Olkin Measure of Sampling Adequacy & 0.600 \\
\hline & Approx. Chi-Square & 267.727 \\
Bartlett's Test of Sphericity & df & 55 \\
& Sig. & 0.000 \\
\hline
\end{tabular}

${ }^{\mathrm{a}}$ Based on correlations.

Second, principal component analysis was performed, and the components with a characteristic value greater than 1 were obtained by the factor rotation mode of the maximum variance rotation. Four variables were extracted from among all the variables, and the factor loading was generally greater than the standard of 0.5 . The cumulative value of these common factors as a percentage of total variance was $66.4 \%$, and the number of common factors was basically in line with the anticipated latent variables. However, the analysis excluded four observable variables: C4, S4, M4, and O3 (Table 2). Therefore, 4 latent variables and 11 observable variables were ultimately entered into the model. Third, the 11 observable variables of the revised model were verified by composite reliability (CR) and average variance extracted (AVE) (Table 5), and the CR of the latent variables was calculated to be above 0.6. It is generally believed that if the CR of latent variables is above 0.6 , the intrinsic quality of the model is good; thus, the quality of this model is ideal. AVE is a ratio, and the larger the value, the more effective the measurement indicators are for the latent characteristics of their common factors [53]. Most of the values in the table are greater than 0.5 -only one is slightly below 0.5 . Thus, the intrinsic quality of the model is good. Finally, the reliability of each level of the survey data was analyzed. According to the Cronbach's $\alpha$ coefficient (CA), the reliability of this questionnaire is adequate (Table 5).

Table 5. The reliability and validity analysis results.

\begin{tabular}{|c|c|c|c|c|c|c|}
\hline Latent Variables & Observable Variables & $\begin{array}{c}\text { Standardized } \\
\text { Factor Loadings } \lambda\end{array}$ & CA & $\begin{array}{l}\text { Measurement } \\
\text { Errors }\end{array}$ & CR & AVE \\
\hline \multirow{3}{*}{$\begin{array}{l}\text { Living conditions of } \\
\text { the courtyard }\end{array}$} & C1 Number of households & 0.85 & 0.72 & 0.28 & \multirow{3}{*}{0.82} & \multirow{3}{*}{0.6} \\
\hline & C2 Number of people & 0.97 & 0.94 & 0.06 & & \\
\hline & C3 Number of strangers & 0.46 & 0.21 & 0.79 & & \\
\hline \multirow{3}{*}{$\begin{array}{l}\text { Living conditions of } \\
\text { one's own house }\end{array}$} & S2 Number of rooms & 0.58 & 0.34 & 0.66 & \multirow{3}{*}{0.71} & \multirow{3}{*}{0.5} \\
\hline & S1 Area of one's own house & 0.92 & 0.85 & 0.15 & & \\
\hline & S3 Property rights & 0.47 & 0.22 & 0.78 & & \\
\hline \multirow{3}{*}{$\begin{array}{l}\text { Identification with } \\
\text { harmonious culture }\end{array}$} & $\begin{array}{l}\text { M1 Use pattern of public } \\
\text { spaces }\end{array}$ & 0.97 & 0.94 & 0.06 & \multirow{3}{*}{0.64} & \multirow{3}{*}{0.5} \\
\hline & M2 Forms of mutual assistance & 0.40 & 0.15 & 0.85 & & \\
\hline & M3 Proportion of public space & 0.40 & 0.16 & 0.84 & & \\
\hline \multirow{2}{*}{$\begin{array}{l}\text { Organization in the } \\
\text { courtyard }\end{array}$} & $\begin{array}{l}\text { O1 Support for conflict } \\
\text { resolution }\end{array}$ & 0.53 & 0.28 & 0.72 & \multirow[t]{2}{*}{0.43} & \multirow[t]{2}{*}{0.3} \\
\hline & $\begin{array}{l}\text { O2 Ability to cope with } \\
\text { unanticipated problems }\end{array}$ & 0.51 & 0.26 & 0.74 & & \\
\hline
\end{tabular}

\subsection{Model Correction and Index Test}

The refined model was examined, and some indicators did not meet the test criteria. Thus, the model needed to be corrected. First, the theoretical significance of the model must be considered during correction. Second, it is necessary to add or delete paths according to the modification index (MI) and the $t$ value (critical ratio) to improve the model fit and make the model more parsimonious. Paths are added when the preferred MI value is at maximum; paths are deleted when the preferred $t$ value is at minimum. According to these principles, the path from "living conditions of one's own house" to "living conditions of the courtyard" was added and tested according to the MI value. This change resulted in one pair of variables becoming connected, causing other MI values to change. After the test, the chi-square value was reduced (chi-square $=48$ ), so the correction was meaningful. However, some indicators still did not meet the criteria and needed to be corrected, as indicated by 
the minimum value of $t$. Thus, the path from "organization in the courtyard" to "identification with a harmonious culture" was deleted. The process of path modification and model correction is shown in Figure 7. The second modified model was analyzed and tested using the maximum likelihood method. According to the results, the model is convergent and identifiable. The chi-square value $=48.973$, indicating no significant increase and that path deletion is feasible. The Df and $p$ values met the criteria. The error values of the potential and observable variables of the model were both positive and reached 0.05 , and the standard deviation of the variance was relatively small, indicating no model definition error and no model violation of the recognition rules. The corrected standardized parameter estimation path model is shown in Figure 8. The other values of the test met the standard (the model adaptation table is shown in Table 6); therefore, the model has good fit and is parsimonious.

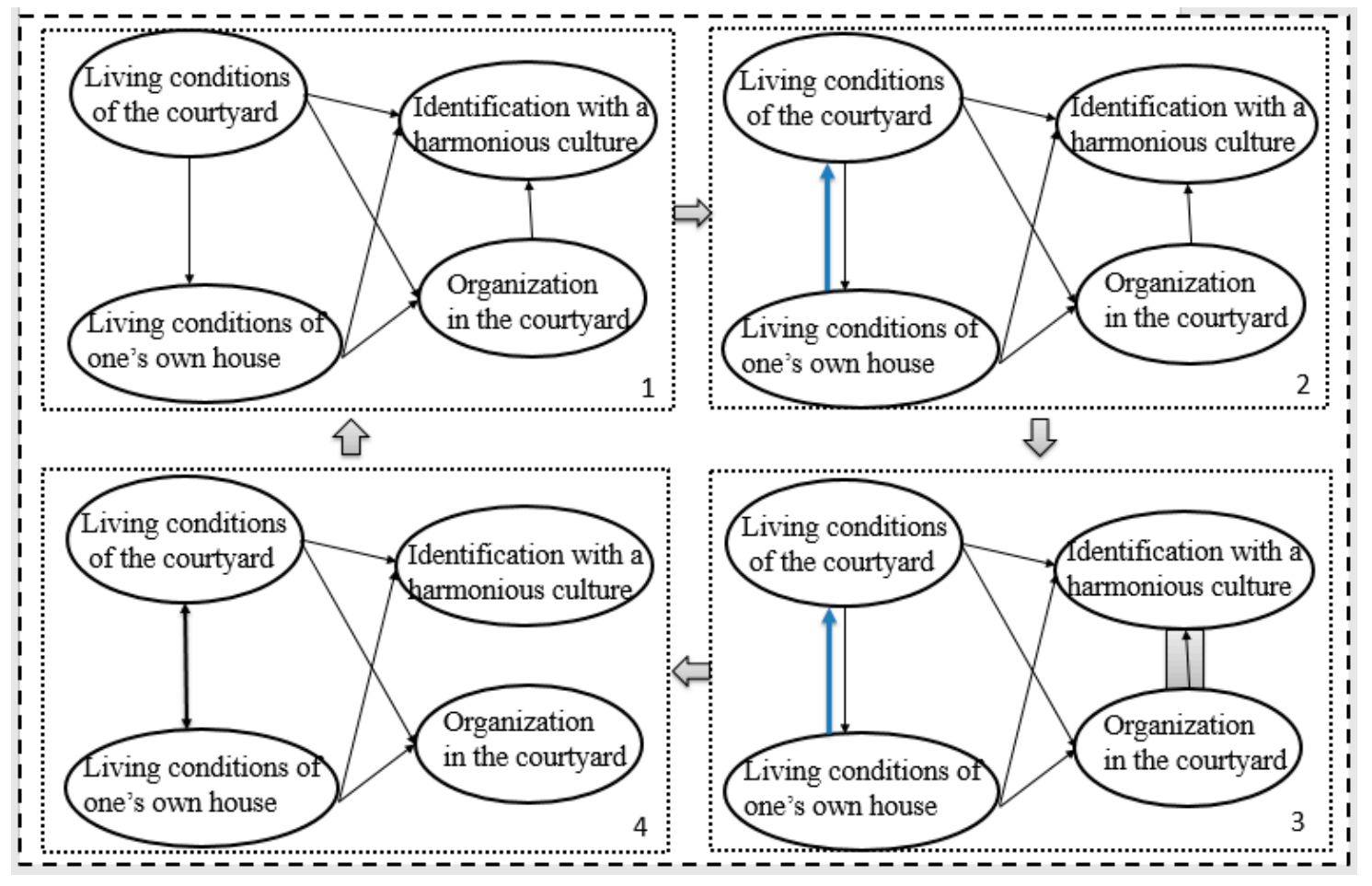

Figure 7. Path modifications and model correction.

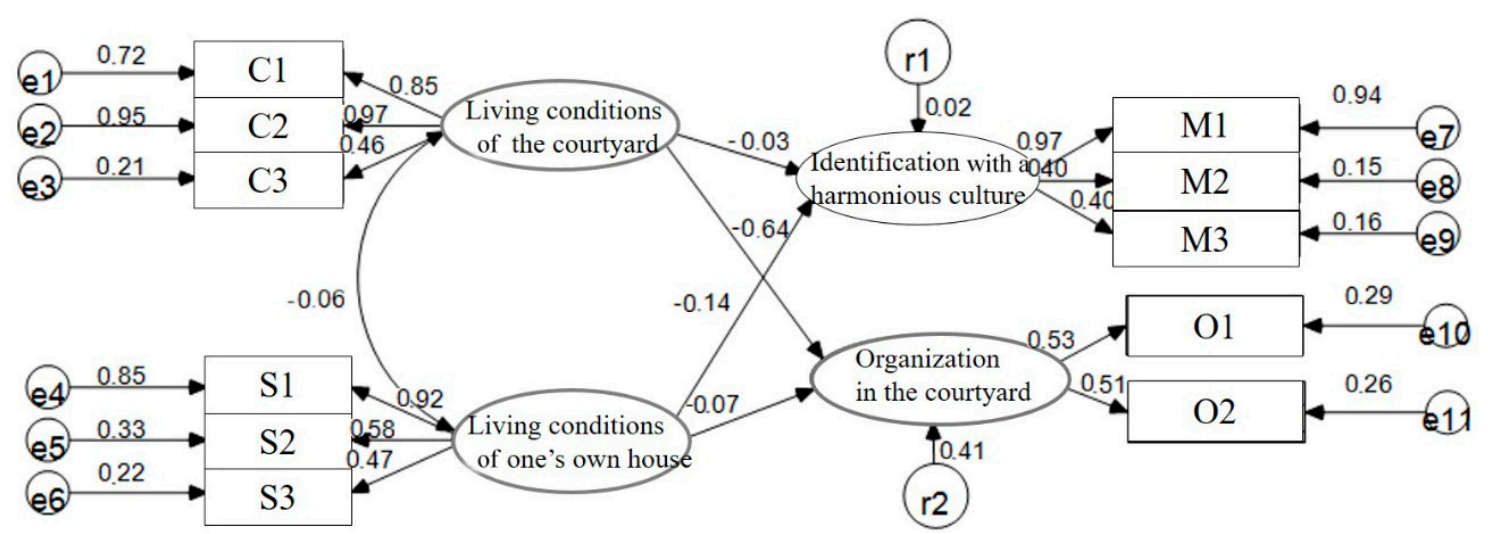

Figure 8. The corrected standardized parameter estimation path model (e1 . . . . e11 are the measurement errors which were generated when the observed variables estimated for latent variables. Values above arrows are the factor loading. It refers to the load of a variable on a common factor, which is also the correlation coefficient between the variable and the common factor). 
Table 6. The model's degree of fit.

\begin{tabular}{|c|c|c|c|c|}
\hline & Data Name & Adaptation Criterion & Data Value & $\begin{array}{l}\text { Adaptation } \\
\text { Judging }\end{array}$ \\
\hline \multirow{4}{*}{$\begin{array}{l}\text { Absolute } \\
\text { Adaptation }\end{array}$} & $\chi^{2}$ (Chi-square) & $>0.05$ & 48.973 & Yes \\
\hline & $\begin{array}{l}\text { RMSEA (Root Mean Square } \\
\text { Error of Approximation) }\end{array}$ & $<0.08$ & 0.05 & Yes \\
\hline & GFI (Goodness of fit Index) & $>0.9$ & 0.925 & Yes \\
\hline & $\begin{array}{l}\text { AGFI (Adjusted Goodness of } \\
\text { fit Index) }\end{array}$ & $>0.9$ & 0.9 & Yes \\
\hline \multirow{3}{*}{$\begin{array}{l}\text { Incremental } \\
\text { Adaptation }\end{array}$} & IFI (Incremental Fit Index) & $>0.9$ & 0.959 & Yes \\
\hline & TLI (Tacker-Lewis Index) & $>0.9$ & 0.937 & Yes \\
\hline & CFI (Comparative Fit Index) & $>0.9$ & 0.956 & Yes \\
\hline \multirow{5}{*}{$\begin{array}{c}\text { Simple } \\
\text { Adaptation }\end{array}$} & $\begin{array}{l}\text { PGFI (Parsimony Goodness of } \\
\text { fit Index) }\end{array}$ & $>0.5$ & 0.546 & Yes \\
\hline & $\begin{array}{l}\text { PNFI (Parsimony-adjusted } \\
\text { Normed Fit Index) }\end{array}$ & $>0.5$ & 0.585 & Yes \\
\hline & $\begin{array}{l}\text { PCFI (Parsimony-adjusted } \\
\text { Comparative Fit Index) }\end{array}$ & $>0.5$ & 0.678 & Yes \\
\hline & $\begin{array}{l}\chi^{2} / \mathrm{df} \text { (Chi square degree of } \\
\text { freedom ratio) }\end{array}$ & $<2$ & 1.256 & Yes \\
\hline & $\begin{array}{l}\text { CAIC (Consistent Akaike } \\
\text { Information Criterion) }\end{array}$ & $\begin{array}{l}\text { The theoretical model value is less } \\
\text { than that of the independent } \\
\text { model, and the two are less than } \\
\text { that of the saturated model }\end{array}$ & $\begin{array}{l}201.372<342.047 \\
342.047<372.530\end{array}$ & Yes \\
\hline
\end{tabular}

\section{Results}

(1) "Identification with a harmonious culture" is positively affected by "the proportion of public space", "forms of mutual assistance", and "use pattern of public spaces", but according to the factor loading, the size of the impact differs. "Identification with a harmonious culture" is more positively affected by the first two observable variables than the third one, and it is more positively affected by the first one than the second one. In other words, the smaller the proportion of public space, the less mutual assistance and the less identification the residents have with the harmonious culture of courtyards in the Xisi area of Beijing. The forms of mutual assistance in the neighborhood are sharing food, helping care for the elderly and children, helping to look after the poor, and borrowing things from each other, etc. The public spaces have many uses, and residents can be found drinking tea and chatting, playing chess, airing out clothing, storing bikes, and stacking sundry items there, as well as using the space as a corridor.

(2) Strengthening people's identification with residential culture requires controlling the population of a compound within a reasonable range. "Identification with a harmonious culture" is negatively affected by "living conditions of the courtyard" and "living conditions of one's own house" (thus, the opposite of $\mathrm{H} 2$ and $\mathrm{H} 3$ is true), and this variable is not positively affected by the organization in the courtyard. "Living conditions of the courtyard" is affected by the number of strangers, the number of households and the number of people in the courtyard. "Living conditions of one's own house" is affected by property rights, the number of rooms and the area of one's own house. According to the path coefficients among the latent variables and factor loading between the latent and observable variables, "identification with a harmonious culture" is primarily affected by the number of people in the courtyard, the number of households, and the number of strangers. It is secondarily affected by the area of one's own house, the number of rooms and property rights. The variables are ranked according to the size of their impact on a harmonious cultural identity. On the whole, "identification with a harmonious culture" is mainly influenced by the first three factors. Therefore, the greater the number of people in the courtyard, the number of households, and the number of strangers, the less identification the residents have with harmonious courtyard culture. Thus, greater population density in courtyards 
affects residents' identification with residential culture. Strengthening people's identification with residential culture requires controlling the population of a compound within a reasonable range.

\section{Conclusions and Discussion}

\subsection{Conclusions}

A flowchart of the logic of the paper is presented in Figure 9. We draw two main conclusions from our case study.

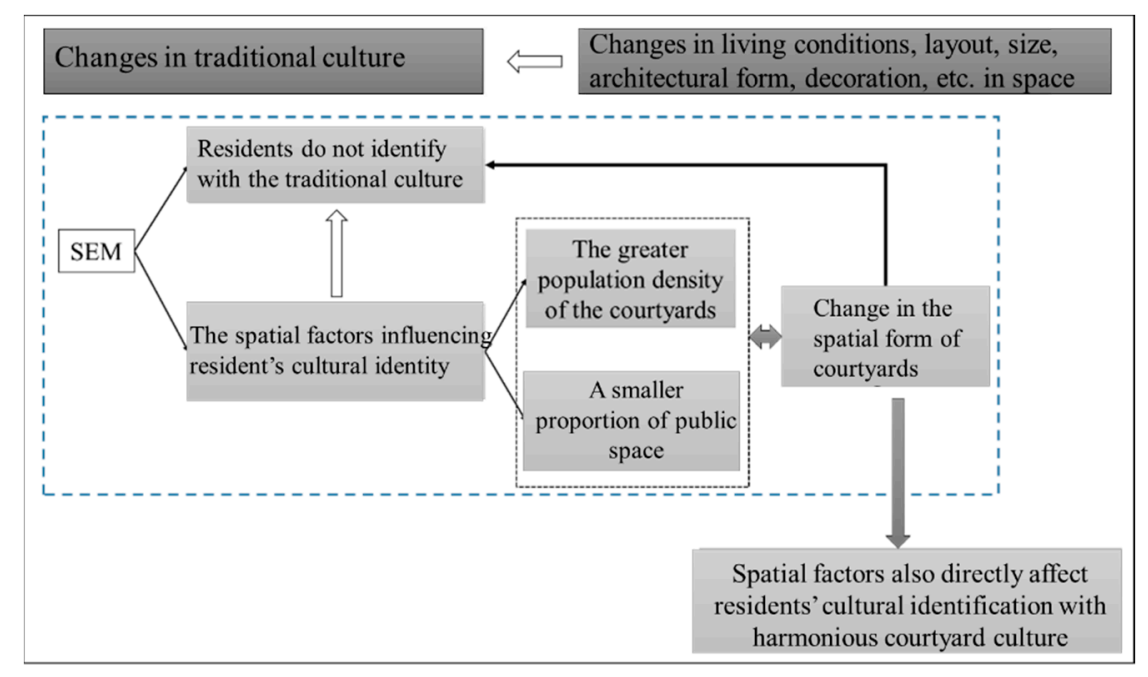

Figure 9. A logical flowchart of the study.

First, the small proportion of public space is the main factor affecting residents' identification with the harmonious residential culture of the case area. When the public space is small, it cannot be used for public exchanges and emotional connections, to exchange material and information and experience nature, or to carry on leisure activities, and courtyard decoration must be limited. Therefore, the proportion of public space in courtyards should be increased to strengthen residents' identification with the harmonious culture of the quadrangle courtyard.

Second, the high population density of the courtyards is another main factor affecting residents' identification with the harmonious residential culture of the case area. The population density of quadrangle courtyards in the case area should be reasonably reduced. With decreased density, residents can actively carry out mutual aid activities, thereby engaging in social interaction. For example, they can care for the old and the young, ensure courtyard safety, and engage in other activities that promote the creation of a comfortable and safe space and strengthen residents' identification with a harmonious courtyard culture.

\subsection{Discussion}

Changes in the living conditions, layout, size, architectural form, decoration, and other spatial aspects of the courtyards led to changes in the traditional culture of the courtyards, preventing them from reflecting the original residential culture and thereby leading to a decline in cultural identity. Therefore, it is necessary to maintain the original architecture and living conditions in these spaces in order to preserve and pass on the original residential culture. Abu-Rabia-Queder and Karplus adopted a geographic perspective and showed that Arab-Bedouin culture has experienced profound spatial changes as a result of forced displacement and state-induced processes of resettlement and urbanization. This has eroded the range of cultural roles held by Bedouin women and has led to gradual changes in their cultural identity [54]. In order to maintain the original architecture 
and living conditions, the proportion of public space in the courtyards should be increased, the population density should be reduced, and non-local residents should be encouraged to move. However, if these out-of-towners moved out of the courtyards, the city's public space would be gradually homogenized [55]. As Tolerance and Jacobs asserted, it is possible and normal for the streets of great cities to allow strangers to dwell in peace together on civilized but essentially dignified and reserved terms. According to Wessel, under homogenization, there would be little or no intergroup contact in space, and people would easily fall prey to prejudice [56]. Thus, how many locals and how many out-of-towners should a courtyard have among its residents? Can the cultural diversity of the courtyard be preserved and the conditions that reflect the original residential culture simultaneously maintained? Moreover, would social justice and greater equality be compromised if the out-of-towners were encouraged to move out of the courtyards in an effort to preserve traditional residential culture? These are issues that need to be discussed in the future.

Author Contributions: Z.C. wrote most of the paper, collected the original sources and data, and created the figures and tables. S.Z. and B.Z. wrote parts of the paper.

Funding: This research is supported jointly by the Project of Beijing Social Science Fund (17JDLSB004), the Project of Institute of Beijing Studies (BJXJD-KT2017-YB11), and the Project of NSFC (Nos. 41371158, 41771148).

Acknowledgments: We are very grateful to Wayne Jones from the USA for his language editing.

Conflicts of Interest: The authors declare no conflict of interest.

\section{References}

1. Lash, S.; Featherstone, M. Recognition and difference: Politics, identity, multiculture. Theor. Cult. Soc. 2001, 18, 1-19. [CrossRef]

2. Della, D.; Diani, M. Social Movements: An Introduction, 2nd ed.; John Wiley and Sons Ltd.: Hoboken, NJ, USA, 2009; pp. 12-16. ISBN 9781405102827.

3. Bucher, S.; Ištoková, M. Self-governing regions in Slovakia: Spatial differentiation and perception of socio-cultural identity by local and regional officials. Geografie 2015, 120, 1-25.

4. Bastian, R.W. Commonplaces: Community ideology and identity in American culture. Soc. Forces 1991, 69, 928-929. [CrossRef]

5. Painter, J. Multilevel citizenship, identity and regions in contemporary Europe. In Transnational Democracy: Political Spaces and Border Crossings; Anderson, J., Ed.; Routledge: London, UK, 2002; pp. 93-110. ISBN 0415223431.

6. Schwartz, S.; Montgomery, M.J.; Briones, E. The role of identity in acculturation among immigrant people: Theoretical propositions, empirical questions, and applied recommendations. Hum. Dev. 2006, 49, 1-30. [CrossRef]

7. Lazerwitz, B. Some Factors in Jewish Identification. Jew. Soc. Stud. 1953, 15, 3-24.

8. Segalman, R. Jewish Identity Scales: A Report. Jew. Soc. Stud. 1967, 29, 92-111.

9. Driedger, L. In search of cultural identity factors: A comparison of ethnic students. Can. Rev. Sociol. 1975, 12, 150-162. [CrossRef]

10. Gupta, S.; Bhugra, D. Cultural identity and its assessment. Psychiatry 2009, 8, 333-334. [CrossRef]

11. Gold, P. Identity formation in Gibraltar: Geopolitical, historical and cultural factors. Geopolitics 2010, 15, 367-384. [CrossRef]

12. Shewly, H. Life, the Law and the Politics of Abandonment: Everyday Geographies of the Enclaves in India and Bangladesh. Ph.D. Thesis, Durham University, Durham, UK, 2012.

13. Szulenyiova, K. Between Cabinda and Oecussi: The Role of Territory in Intrastate Relations. Master's Thesis, University of Cambridge, Cambridge, UK, 2012.

14. Lahoud, A.L. The role of cultural (architecture) factors in forging identity. Natl. Identities 2008, 10, 389-398. [CrossRef]

15. Martinez-Quintana, L.; Caceres-Morales, E. Urban growth and cultural identity; fractures and imbalances in heritage values: A case study of the island of Saint-Louis, Senegal. Isl. Stud. J. 2016, 11, 291-307.

16. Nechitaylo, V. Folk choreographic art of Ukraine as the important factor of the formation of the national cultural identity. Вісник Національної Академії Керівних Кадрів Культури і Мистецтв 2017, 1, 128-133. 
17. Schwartz, S.J.; Zamboanga, B.L.; Rodriguez, L.; Wang, S.C. The structure of cultural identity in an ethnically diverse sample of emerging adults. Basic Appl. Soc. Psychol. 2007, 29, 159-173. [CrossRef]

18. Beijing Planning Committee. Conservation Planning of 25 Historic Areas in Beijing Old City; Beijing Yanshan Press: Beijing, China, 2002; pp. 10-15. ISBN 7540214740.

19. Duan, B. Beijing Courtyard; Beijing Publishing House: Beijing, China, 2015; p. 20. ISBN 9787200115918.

20. Gao, W. The "rules" in the courtyard embodies the harmonious relationship between human and nature. Chinese Social Science News, 16 November 2012.

21. Gu, J.; Wang, L. Try to talk about Beijing Siheyun architectural features. In Beijing Cultural History Research; Zhu, Y., Ed.; Guangming Daily Press: Beijing, China, 2008; pp. 108-109. ISBN 9787802065864.

22. Zhen, J. Tian Zhi Ou Wen; Beijing Ancient Books Publishing House: Beijing, China, 1982; p. 10.

23. Rubidge, S. Nomadic diagrams: Choreographic topologies. Choreogr. Pract. 2011, 1, 43-56. [CrossRef]

24. Zhou, S.; Xia, H.; Cheng, Z. The identity and heritage for Beijing Siheyuan residential culture spaces. In China's Urban Research Series 9; Ning, Y., Ed.; Science Press: Beijing, China, 2016; pp. 122-134. ISBN 7030503848.

25. Lu, X.; Wang, Q. Beijing Courtyard Atlas; China Building Industry Press: Beijing, China, 1996; p. 3. ISBN 9787112022960.

26. Zhu, Z.; Yuan, J. The Important Place of Beijing; China Tourism Press: Beijing, China, 2015; p. 150. ISBN 9787503247088.

27. Li, F. The Communist Party of China's Traditional Cultural View Research; The History of the Communist Party of China Press: Beijing, China, 2008; pp. 324-325. ISBN 9787509800614.

28. Zhang, J. Pursuit harmonious culture essence in construction-Read Beijing Siheyuan. Art Educ. 2011, 33, 158.

29. Ellis, G.; Barry, J.; Robinson, C. Many ways to say 'no', different ways of saying 'yes': Applying Q-methodology to understand public acceptance of wind farm proposals. J. Environ. Plan. Manag. 2007, 50, 517-551. [CrossRef]

30. Stedman, R.C. Toward a social psychology of place: Predicting behavior from place-based cognitions, attitude, and identity. Environ. Behav. 2002, 34, 561-581. [CrossRef]

31. Wu, M. SEM-The Operation and Application of AMOS; Chongqing University Press: Chongqing, China, 2009; pp. 1-20. ISBN 9787562457206.

32. Huang, R. The Data, the Principle and Application of SPSS Statistical Analysis; Higher Education Press: Beijing, China, 2010; p. 282. ISBN 9787040296006.

33. Pettigrew, T.F. Intergroup contact theory. Annu. Rev. Psychol. 1998, 49, 65-85. [CrossRef] [PubMed]

34. Allport, G.W. The Nature of Prejudice; Addison-Wesley Publishing Company: Cambridge, MA, USA, 1954; pp. 22-24. ISBN 0201001756.

35. Xue, R. Retrofit Design Research for Courtyard on the Premise of Population Relief. Master's Thesis, Beijing Institute of Civil Engineering and Construction, Beijing, China, 2012.

36. Michelson, W. Research note: An empirical analysis of urban environmental preferences. J. Am. Inst. Plan. 1966, 32, 355-360. [CrossRef]

37. Hanif, E.; Hashemnejad, H.; Ghafourian, M. The concept of sustainable dwelling epitomized in the courtyards of Iranian houses: A case study of houses in Kashan in the Qajar Period. J. Eng. Appl. Sci. 2017, 12, 1482-1491. [CrossRef]

38. Muller, M.S. Traditional Cultural Identity in New Dwellings of Urban Africa. Ekistics 1984, 51, 359-365.

39. Li, Y.; Guo, Y.; Chong, J. The investigation of old city's oblique streets and advices on its development programming. J. Beijing Union Univ. 2004, 1, 15-20. [CrossRef]

40. Plummer, J. Municipalities and Community Participation: A Sourcebook for Capacity Building; Earthscan: London, UK, 1999; pp. 32-34. ISBN 9781853837449.

41. Carmona, M.; De Magalhaes, C.; Hammond, L. Public Space: The Management Dimension; Routledge: London, UK, 2008; pp. 17-20. ISBN 9780415391085.

42. Jiao, Y. Community Development: The Feasible Way to Protect and Improve for Beijing Old City Historical Culture Protection. Ph.D. Thesis, Tsinghua University, Beijing, China, 2003.

43. Wang, L. The Theory and Practice Research for Beijing Residents "Participation" in the Historical Culture Protection Planning. Ph.D. Thesis, Tsinghua University, Beijing, China, 2003.

44. Smith, D.L. Household Design and Family Needs in Nairobi, Kenya. Ekistics 1981, 48, 145-151.

45. Cui, H.; Yu, Z. Value and inheritance of space pattern of Beijing courtyard. Value Eng. 2013, 110-111. [CrossRef] 
46. Wang, Z. The Modernity of Historical Block; Guangxi Normal University Press: Guilin, China, 2015; p. 208. ISBN 9787549568703.

47. Liu, Y. Beijing's Traditional Courtyard Space Research on Organic Renewal and Reconstruction. Master's Thesis, Beijing Forestry University, Beijing, China, 2010.

48. Zhou, K.; Zhang, D. Beijing Siheyuan courtyard space and function's contemporary replacement. In Communities, Settlement, Construction, the Special Conference Proceedings for the16th World Congress of the International Federation for Anthropology and Ethnology; Research on China's National Construction Groups, Ed.; Yunnan University Press: Yunnan, China, 2009; pp. 522-526. ISBN 9787811129663.

49. Yuan, X. The changes of the modern Beijing residents living conditions. In The Capital Museum Periodicals Issue 18; The Capital Museum, Ed.; Beijing Yanshan Press: Beijing, China, 2004; pp. 37-41. ISBN 9787540208806.

50. Levin, J.; Fox, J.A. (Eds.) The Basic Statistics in Social Research; Wang, W., Translator; Chinese People's Publishing House: Beijing, China, 2008; pp. 167-171. ISBN 9787300090559.

51. Philosophy and Social Science Achievement Evaluation Committee in Liaoning Province (Ed.) Liaoning Province Philosophy Social Sciences Work on Assembly of 2003-2004; Liaoning People's Publishing House: Shenyang, China, 2007; p. 448. ISBN 7205061539.

52. Liu, Z.; Wu, G. SPSS Statistical Analysis and Application; Electronic Industry Press: Beijing, China, $2011 ;$ p. 365. ISBN 9787121126871.

53. Zhang, L. The Low Carbon Behavior Affecting factors and the Mechanism in City Tourism Hotel. Ph.D. Thesis, Dalian University of Technology, Dalian, China, 2014.

54. Abu-Rabia-Queder, S.; Karplus, Y. Regendering space and reconstructing identity: Bedouin women's translocal mobility into Israeli-Jewish institutions of higher education. Gend. Place Cult. 2013, 20, 470-486. [CrossRef]

55. Sorkin, M. Variations on a Theme Park: The New American City and the End of Public Space; Hill and Wang: New York, NY, USA, 1992; pp. 7-9. ISBN 0809096072.

56. Wessel, T. Does diversity in urban space enhance intergroup contact and tolerance? Geogr. Ann. 2009, 91, 5-17. [CrossRef]

(c) 2018 by the authors. Licensee MDPI, Basel, Switzerland. This article is an open access article distributed under the terms and conditions of the Creative Commons Attribution (CC BY) license (http://creativecommons.org/licenses/by/4.0/). 